\title{
Obstetric accidents: a review of 64 cases
}

\author{
M Ennis, C A Vincent
}

\begin{abstract}
Objective-To identify the causes of obstetric accidents.

Design and setting-Analysis of case records at the Medical Protection Society's London office covering the five years 1982-6.

Subjects - Cases that had come to litigation which had resulted in stillbirth, perinatal or neonatal death, central nervous system damage to the baby, or maternal death and in which there was an opinion from a senior obstetrician consulted by the society. Of 147 cases reviewed, 64 met the criteria for the study.
\end{abstract}

Main outcome measures-The principal findings of the expert reviewers.

Results - Three major topics of concern emerged common to most of the 64 cases. These were inadequate fetal heart monitoring, mismanagement of forceps, and inadequate supervision by senior staff. In 11 of the 64 cases cardiotocography was omitted, in 19 cases the trace was missing, in six cases the trace was unreadable, and in 14 of the remaining 28 cases signs of fetal distress went unnoticed or were ignored. In $\mathbf{3 1}$ cases forceps were used to aid delivery or were tried and abandoned in favour of caesarean section. In $\mathbf{1 6}$ cases two or more attempts to use forceps were made. Five infant deaths were directly attributed to mismanaged forceps. In 20 cases senior staff were criticised by the expert reviewer for failure to come to the labour ward. In many of these cases they may have given advice over the telephone, but the inadequacy of records made it impossible to tell. In these cases the labour and birth were managed by junior staff, usually a senior house officer. In six cases when senior staff did come they suggested that no action was needed.

Conclusion-These few cases should not be dismissed as isolated incidents in obstetric practice in Britain. They reflect more general problemsnamely, concerning the ability of junior doctors to interpret fetal heart traces accurately, their ability to use forceps, and the participation of senior staff in running a labour ward and delivery suite.

\section{Introduction}

Medical litigation is increasing and obstetrics and gynaecology accounts for $30 \%$ of all claims of negligence against health authority doctors. ${ }^{\prime}$ Though obstetricians make up only $3 \%$ of the membership of the Medical Protection Society, they account for $29 \%$ of costs and damages.' Stillbirth and brain damage account for almost half of these claims. ${ }^{3}$ Obstetric accidents which come to litigation are only a small proportion of the total. Individual departments' clinical reports, perinatal mortality meetings, and even day to day working in the labour ward or delivery suite will identify other incidents of error, real and potential. There is a clear need for research into the causes of these accidents.

In the worlds of aviation, ${ }^{4}$ road and rail transport, ${ }^{5}$ and industry in general ${ }^{6}$ accidents and error are the subject of systematic study. In contrast, systematic investigation of accidents in medicine is extremely rare. Though many hospital departments carry out regular audits of practice, information on errors and accidents is seldom published. Obstetricians are more forward looking in this respect than most clinicians.

The most recent confidential inquiry into maternal death $s^{8}$ comments on cases of inadequate care, but it is not an inquiry into accidents as such. Most other studies comment on avoidable accidents only from a medicolegal viewpoint and make no attempt to investigate the accidents themselves. ${ }^{9}$ This survey of obstetric cases held on file at the Medical Protection Society's London office was carried out to determine the common factors in obstetric accidents, to identify their causes, and to develop methods of prevention.

\section{Subjects and methods}

We initially reviewed all serious obstetric cases occurring in the British Isles involving litigation reported to the Medical Protection Society over the five years 1982-6. A case was defined as serious when the outcome was either stillbirth, or perinatal or neonatal death, or central nervous system damage leading to handicap, or maternal death. There were 147 cases which met these criteria. The Medical Protection Society uses a panel of senior doctors to give expert obstetric opinion on all cases that it deals with. We used the presence of an expert opinion as a further criterion. At the time of study 73 cases had not been submitted for an expert opinion. Reasons were that no formal action had been taken, there was doubt whether patients or relatives would proceed with litigation, or Medical Protection Society members were so peripherally implicated that an expert opinion was not deemed necessary. In 10 of the remaining 74 cases the expert considered that the member had proceeded correctly in every way and that no intervention on his or her part could have altered events. The remaining 64 cases were carefully reviewed.

Using a form devised for the study we collected data on the nature of claims, outcome, grade of reporting doctor, mother's age, parity, previous obstetric history, antenatal history in the relevant pregnancy, problems during labour, attention received from both junior and senior doctors during the labour, method of delivery, the condition of the baby at birth, and, when relevant, cause of death. Factual information was taken from copies of the original notes or from the expert's report. All assessments of standard of care and causes of the accidents are those of the expert reviewers. Though we endeavoured to provide a comprehensive account of the birth and any attendant problems, we and the expert reviewers were limited by the adequacy of records collected at the time. The figures presented are therefore likely to underestimate the true incidence of problems in these cases.

\section{Results}

\section{GRADE OF REPORTING DOCTOR}

Table I shows the grade of doctor initially contacting the Medical Protection Society. The reporting doctor is usually the one primarily concerned in the accident, though occasionally a senior doctor in a supervisory
Correspondence to:

Br.Med f 1990;300:1365-7 
capacity may report it on behalf of his or her junior. In this series over half of the reporting doctors were obstetricians in training, though not all the senior house officers were career obstetricians. The "other" category included two anaesthetists, two paediatricians, and a general practitioner.

\section{MOTHERS}

Demographic data and previous history-Table II gives demographic data on the mothers and their relevant history. The mean age of the mothers was 27 (SD 6-2) years (range 17-39). Only six were under 20 and seven over 35 (none aged 40 or over), so that maternal age seemed not to be an appreciable risk factor in these cases. In only 15 cases was a past history of perinatal adversity reported and only 14 mothers had antenatal complications. Five mothers had both a previous history of perinatal adversity and antenatal complications. Hence these groups did not seem to be at particularly high risk. No correlations were found between previous perinatal adversity and outcome or between antenatal complications and outcome. In seven cases a note was made of previous adversity but no details were recorded.

Procedures during labour - Labour was induced in 24 cases, and 26 women were delivered by caesarean section. Table III shows the indications for induction and operation.

\section{OUTCOME}

Mothers-Four mothers died. Two died of a ruptured uterus, one of septicaemia, and one of toxic shock. In one case a ruptured uterus was not diagnosed for three days, during which the patient was given transfusion and seen by several doctors. In two other cases severe lacerations of the uterus sustained during delivery necessitated hysterectomy and death was a consequence of inappropriate management of the patient after this procedure.

Babies - Nineteen babies failed to survive. Table IV gives the details and causes of death. The remaining 45 babies suffered some degree of neurological damage. The degree of impairment could not usually be determined from records kept by the Medical Protection Society.

TABLE I-Grades of doctors initially contacting Medical Protection Society in the 64 cases

\begin{tabular}{cccccccc}
\hline & $\begin{array}{c}\text { Senior } \\
\text { house } \\
\text { officer }\end{array}$ & Registrar & $\begin{array}{c}\text { Senior } \\
\text { registrar }\end{array}$ & Consultant & Other & Total \\
\hline No of cases & 17 & 23 & 1 & 16 & 7 & 64 \\
\hline
\end{tabular}

TABLE II-Mothers' histories in the 64 cases (mean age of mothers 27 years, range 17-39)

\begin{tabular}{lc}
\hline & No of cases \\
\hline Parity: & \\
First pregnancy & 35 \\
One previous live birth & 12 \\
Two to four previous live births & 13 \\
Not stated & 4 \\
History of previous perinatal adversity: & 4 \\
Miscarriage & 2 \\
Spontaneous abortion & 2 \\
Infertility over three years & 7 \\
Details not known & \\
Antenatal complications in relevant pregnancy: & 3 \\
Weight loss/poor weight gain & 3 \\
Bleeding & 2 \\
Reduced fetal movement & 3 \\
Known breech or other malpresentation & 3 \\
Very small mother & \\
Gestation (range $34-43$ weeks): & 32 \\
Term (38-42 weeks) & 13 \\
Preterm & 14 \\
Post-term & 5 \\
Not stated & \\
\hline
\end{tabular}

TABLE III - Indications for induction of labour and caesarean section

\begin{tabular}{lc}
\hline & No of cases \\
\hline Induction of labour: & \\
Past term & 8 \\
Pain and vomiting & 1 \\
Fetal distress & 3 \\
Hypertension/pre-eclampsia & 3 \\
Fetus dead & 2 \\
Not known & 7 \\
\hline Total & 24 \\
\hline Caesarean section: & \\
Cord prolapse & 3 \\
Fetal distress & 13 \\
Breech & 3 \\
Arrested dilatation & 1 \\
Not known & 6 \\
\hline Total & 26 \\
\hline
\end{tabular}

TABLE IV-Causes of fetal and infant death (19 cases)

\begin{tabular}{lc}
\hline & No of cases \\
\hline Fetal/infant death: & \\
Stillbirth & 12 \\
Perinatal death (0-7 days) & 5 \\
Neonatal death & 2 \\
Cause of infant death/findings at necropsy: & 5 \\
Anoxia/hypoxia & 1 \\
Respiratory distress syndrome & 1 \\
Diffuse cerebral trauma & 2 \\
Skull fracture & 2 \\
Tentorial tears & 8 \\
Cause not reported & \\
\hline
\end{tabular}

TABLE V - Intrapartum fetal monitoring

\begin{tabular}{lc}
\hline & No of cases \\
\hline Cardiotocography not done & 11 \\
Unsatisfactory trace & 6 \\
Trace recorded but missing & 19 \\
Cardiotocogram abnormality ignored or not noticed & 14 \\
Cardiotocogram abnormality noted and responded to & 14 \\
\hline Total & 64 \\
\hline
\end{tabular}

\section{STANDARD OF CARE}

Assessment of labour - In six cases the onset of labour was not correctly diagnosed, three of these cases being a failure on the part of the midwives. The mothers were consequently not moved to the delivery suite in time. In a further three cases mothers already in labour were given prostaglandins to induce labour by senior house officers. Five patients were not visited at all by doctors, also resulting in dangerous delay in initiating appropriate treatment. No reason for these delays could be ascertained from the records.

Fetal heart monitoring-In 11 of the 64 cases no electronic fetal monitoring was undertaken. These included three cases in which midwives were asked by a doctor to carry out cardiotocography but forgot. In a further 19 cases the trace was missing. This was not necessarily a sinister finding as many of these traces may have been taken for teaching. The results are based on the remaining cases, and table $\mathrm{V}$ lists the main problems. In 14 cases signs of fetal distress were either not noticed or were noted but ignored. We could not tell which. In three of the cases an abnormality was correctly noted by the midwife but ignored by the doctor, raising questions about communication between doctor and midwife.

Forceps assisted delivery-Forceps were used in 31 cases (table VI). They were either used to aid delivery or tried and abandoned in favour of caesarean section. In almost all cases the indication for forceps was delay in the second stage (12 cases) or fetal distress (15). In many cases these complications occurred together, and when this was so the more prominent indication 
was chosen. In only two cases was the indication rotation of the fetal head. Frequent criticisms by the Medical Protection Society's experts were of the number of attempts to use forceps to assist delivery and of the use of undue traction (table VI). Five infant deaths were directly attributed to mismanaged forceps, and one maternal death was indirectly caused by misuse of forceps. In none of the cases was vacuum extraction used.

TABLE VI - Instrumental (forceps) deliveries (31 cases)

\begin{tabular}{lc|lc}
\hline Indications & No of cases & $\begin{array}{l}\text { No of forceps } \\
\text { attempts }\end{array}$ & No of cases \\
\hline Fetal distress & 15 & 1 & 6 \\
Delay in second stage & 12 & 2 & 13 \\
Not known & 2 & 3 & 3 \\
Rotation of fetal head & 2 & Not known & 9 \\
\hline
\end{tabular}

TABLE VII - Presence of senior staff at delivery in the 64 cases

\begin{tabular}{lcccc}
\hline & \multicolumn{3}{c}{ Senior staff present } & \\
\cline { 2 - 4 } & $\begin{array}{c}\text { Definitely } \\
\text { no }\end{array}$ & $\begin{array}{c}\text { Definitely } \\
\text { yes }\end{array}$ & $\begin{array}{c}\text { Not } \\
\text { known }\end{array}$ & Total \\
\hline No of cases & 20 & 24 & 20 & 64 \\
\hline
\end{tabular}

Supervision by senior staff-In 20 of the 64 cases the expert reviewer criticised senior staff (senior registrars and consultants) for failing to attend despite being called (table VII). In many cases senior staff may have given advice over the telephone, but nevertheless the labour and birth were managed entirely by a junior doctor, usually a senior house officer. Senior staff did not always recognise the gravity of the problem when they did arrive. In six cases they suggested that no action was needed.

\section{Discussion}

This review of serious obstetric accidents confirms the Department of Health's confidential inquiry into maternal deaths. ${ }^{8}$ Human error was frequently implicated in obstetric accidents, and many were avoidable. Using expert opinion as our guide, we identified three major areas of concern: inadequate fetal monitoring, mismanagement of forceps (that is, undue traction, too many attempts), and inadequate supervision by senior staff. The assessment of labour, by both doctors and midwives, was also criticised in some cases. Junior and middle grade obstetricians were most frequently involved.

Although cardiotocography is widely used in obstetric practice, it seems that some registrars and senior house officers do not recognise abnormal or equivocal traces. In this series 14 of 34 abnormal traces were not identified by junior doctors. Misinterpretation of normal traces is also common (M Ennis, unpublished data). In many cases even when abnormal traces were recognised no appropriate action was taken (for example, seeking advice or carrying out further tests). These findings suggest that middle and junior staff are inadequately trained in fetal heart monitoring and inadequately supervised in the labour ward. Nevertheless, though the senior obstetrician is responsible for ensuring that staff have acquired the basic monitoring skills, it is the responsibility of the staff to ensure that they are properly taught and to seek advice when in doubt. ${ }^{3}$ By virtue of their position, however, senior staff must ultimately be held responsible for everything that happens on the labour ward and delivery suite.

The rates of instrumental delivery in Britain have fallen in recent years. ${ }^{1011}$ Forceps were used in 31 of the 64 cases in this series, but these were a highly selected sample of cases that had come to litigation. More important was that in 16 of the 31 cases there were two or more attempts to use forceps before delivery, sometimes involving several doctors consecutively, with trauma to both mother and infant. Five infant deaths were directly attributable to mismanaged forceps, and misused forceps indirectly caused one maternal death. Repeated attempts to use obstetric forceps by junior doctors is dangerous.

There seems to be inadequate supervision of doctors in the labour ward. Many inexperienced senior house officers are left for long periods alone in labour wards without being visited by registrars and consultants. In two cases in this series consultants had doubts about the competency of junior staff, but despite this no consultant visited the labour ward over a 24 hour period.

The participation of senior staff in the labour ward is a difficult topic. Middle grade and junior staff must learn to make decisions for themselves, yet seniors must be responsible for seeing that these decisions come from proper training and experience. In almost a third of cases the expert reviewer criticised the lack of supervision by senior staff. In some cases the fault lay with junior staff who did not realise that they needed help. Nevertheless, in almost half of cases in which a more senior doctor was called the senior did not come to the ward. Senior staff may not have been asked to come or they may have given advice over the telephone; because of inadequate records it was not possible to tell.

During the five years covered by this review over 3 million babies were born in Britain, and the vast majority of these births were accident free. ${ }^{12}$ The cases in this series could be dismissed as isolated incidents from which little can be learnt. We believe, however, that they reflect more general problems. Preliminary results of a study that we are currently carrying out on cardiotocogram monitoring suggest that senior house officers do not interpret traces accurately and, in addition, are over confident. Our present results suggest that there is also a need to examine junior doctors' ability to use forceps and investigate the extent to which senior staff participate in running a labour ward.

We are grateful to Dr C Orr, Professor R Taylor, and Mr J Drife for their comments on the manuscript, and to Mr Drife for advice on the form used to collect the data. This study forms part of the Medical Protection Society project on avoidable mishaps in medicine under the direction of Professor R J Audley.

1 Orr CJB. Medico-legal aspects of obstetric and gynaecological practice. In: Bonnar J, ed. Recent advances in obstetrics and gynaecology. London: Bonnar J, ed. Recent advonce

Medical Protection Society. Annual report London: MPS, 1989.

3 Brown ADG. Medicolegal aspects of fetal monitoring. In: Spencer JAD, ed. Fetal monitoring - physiology and techniques of antenatal and intrapartum fetal assessment. Tunbridge Wells: Castle House Publications, 1989:233-8.

4 Ricketson DS, Brown WR, Graham KN. 3W Approach to the investigation of the analysis and prevention of human error. Aviat Space Environ Med $1980 ; 51: 1036-42$.

McKenna FP. The human factor in driving accidents. An overview of approaches to problems. Ergonemics 1982;10:867-77.

6 Hale AR, Hale M. A review of the industrial accident literature. London: HMSO, 1972

7 Vincent C. Research into medical accidents: a case of negligence? Br Med $\mathcal{J}$ 1989:299:1150-3.

8 Department of Health. Report on confidential enquiries into matemal deaths in England and Wales. London: HMSO, 1989. 9 Quam L, Dingwall R, Fenn P. Medical malpractice claims in obstetrics and
gynaecology: comparisons between the USA and Britain. Br J Obstet Gynaecol 1988;95:454-6

10 O'Driscoll $\mathrm{K}$, Meagher $\mathrm{D}$. Traumatic intracranial haemorrhage in firstborn infants and delivery with obstetrics forceps. Br f Obstet Gynaecol 1981;88 $577-81$

11 Drife J. Operative delivery-clinical aspects. In: Chamberlain GVP, Orr Cl, Sharp F, eds. Litigation in obstetrics and gynaecology. Proceedings of the 14th study group of the RCOG. London: Royal College of Obstetricians and Gynaecologists, 1985:255-64.

12 Department of Health. Health and personal social services statistics for England London: HMSO, 1989.

(Accepted 9 March 1990) 